\title{
Akuntabilitas dan Transparansi Laporan Keuangan Pada Organisasi Pengelola Zakat: Studi Komparatif di BAZ dan LAZ Yogyakarta
}

\section{Affiliation:}

Universitas Muhammadiyah

Yogyakarta

*Correspondence:

puspita@umy.ac.id

This Article is Avalilable in:

https://journal.umy.ac.id/index.

php/jati/article/view/7306

DOI:

10.18196/jati.030122

\section{Citation:}

Wulaningrum, P., \& Pinanto, A. (2020). Analisis Akuntabilitas dan Transparansi Laporan Keuangan pada Organisasi Pengelola Zakat Berdasarkan PSAK 109.. Jati: Jurnal Akuntansi Terapan Indonesia, 3(1), 15-24.

\section{Article History}

Received:

03 February 2020

Reviewed:

04 March 2020

Revised :

11 March 2020

Accepted:

31 March 2020

Topic Article:

Sector Public Accounting

Syariah Accounting

\author{
Puspita Dewi Wulaningrum*1, Amin Pinanto²
}

\begin{abstract}
:
The research aims at learning about the accountability and transparency as well as the accounting policy on the financial statement of BAZNAS Kota Yogyakarta and Lazismu Kota Yogyakarta in managing zakat, infaq, and shodaqoh funds based on PSAK Number 109. The research used qualitative descriptive method. The data were collected through interviews, observations, and documentation. The analysis method of the research used descriptive qualitative approach, multiple case study, and comparative research. The research result indicates that BAZNAS Kota Yogyakarta has been accountable and transparent in preparing the annual financial statements which comply with PSAK Number 109. This is proven by the complete financial statement components, separate presentation of non-halal funds, on-time statement submission, and that the statements are audited by external institutions. Meanwhile, Lazismu Kota Yogyakarta has not been accountable and transparent based on PSAK 109. This is due to the incomplete financial statements and the fact that the statements have not been published in printed and digital media.
\end{abstract}

Keywords: PSAK 109, Accountability, Transparency

\begin{abstract}
Abstrak:
Penelitian ini bertujuan untuk mengetahui akuntabilitas dan transparansi serta kebijakan akuntansi pada laporan keuangan BAZNAS Kota Yogyakarta dan Lazismu Kota Yogyakarta dalam pengelolaan dana zakat, infaq, dan sedekah sesuai berdasarkan PSAK Nomor 109. Penelitian ini menggunakan metode deskriptif kualitatif. Teknik pengumpulan data menggunakan wawancara, observasi, dan dokumentasi. Metode analisis penelitian ini menggunakan pendekatan deskriptif kualitatif, multiple case study, dan penelitian komparasi. Hasil penelitian menunjukkan BAZNAS Kota Yogyakarta telah akuntabel dan transparan dalam penyusunan laporan keuangan tahunannya sesuai PSAK Nomor 109. Hal ini dibuktikan melalui komponen laporan keuangan yang lengkap, penyajian terpisah dana nonhalal, penyampaian sesuai tenggat waktu, dan diaudit oleh lembaga eksternal. Sedangkan Lazismu Kota Yogyakarta belum akuntabel dan transparan sesuai PSAK 109. Hal ini disebabkan komponen laporan keuangan tidak lengkap dan belum terpublikasinya ke media cetak maupun media digital.
\end{abstract}

Kata Kunci: PSAK 109, Akuntabilitas, Transparansi. 


\section{PENDAHULUAN}

Islam merupakan agama mayoritas penduduk di Indonesia. Islam sendiri memiliki aturan-aturan yang jelas baik mengenai tata cara peribadatan sampai kehidupan sosial umatnya. Hal ini tentu memberikan dampak pada berkembangnya penerapan hukum Islam dan menjamurnya prinsip syariah dalam kehidupan bermasyarakat.

Salah satu penerapan prinsip Syariah yang wajib dilaksanakan oleh umat muslim yang mampu adalah zakat. Muslim yang membayarkan zakatnya disebut muzaki. Zakat yang dibayarkan oleh Muzaki kemudian disalurkan kepada penerima zakat (Mustahik) oleh Amil (penyalur) Zakat. Pengelolaan untuk pembayaran dan penyaluran zakat, infaq, dan sedekah tersebut biasanya dipercayakan kepada Amil zakat.

Zakat merupakan ibadah yang sangat istimewa, karena zakat adalah ibadah yang melibatkan ekonomi setiap muslim yang bertujuan untuk mensucikan diri (Fuadi, 2016). Infaq berarti pengeluaran sedikit/sebagian harta/pendapatan dari hasil muamalah dari sesama manusia untuk mendapatkan ridho/berkah/pahala dari Allah Subhana Wa Ta'ala (Hastuti, 2016). Sedekah adalah harta yang dibagikan secara sukarela oleh si pemilik harta, walau itu ditentukan atau tidak ditentukan secara hukum Islam (Rahman, 2015).

Saat ini Amil zakat sudah banyak yang berbentuk Lembaga atau organisasi. Organisasi Pengelola Zakat (OPZ) terbagi menjadi dua bagian yaitu BAZ (Badan Amil Zakat) dan LAZ (Lembaga Amil Zakat). Perbedaan BAZ dan LAZ adalah pada sisi pengelolanya. BAZ dikelola oleh Pemerintah sedangkan LAZ dikelola oleh pihak swasta. Sedangkan pada sisi legalitas, beberapa OPZ sudah memiliki izin beroperasi secara resmi oleh pemerintah diantaranya adalah BAZNAS (Badan Amil Zakat Nasional), LazisMu (Lembaga Amil Zakat Infaq dan Shodaqoh Muhammadiyah), LAZ Rumah Zakat Indonesia, LAZ Daarut Tauhid, LAZ Nadhlatul Ulama, dan lain-lain (Indrarini \& Surya Nanda, 2017).

Bagi OPZ yang memiliki izin resmi dari pemerintah tentu dalam pengoperasiannya bukan hanya mengikuti syariat islam saja namun tidak lepas dari peraturan perundangan yang berlaku. Awalnya, Pemerintah Indonesia mengesahkan Undang-Undang No.38 Tahun 1999 sebagai dasar perolehan izin beroperasi bagi lembaga zakat yang dibentuk pemerintah (Badan Amil Zakat) maupun lembaga zakat yang dibentuk oleh swasta (Lembaga Amil Zakat). Saat ini, undang-undang tersebut disempurnakan menjadi UU No. 23 Tahun 2011 tentang Pengelolaan Zakat. Dalam UU No. 23 Tahun 2011 ini terdapat aturan tambahan yaitu mengenai Badan Amil Zakat Nasional (BAZNAS) yang ditunjuk sebagai koordinator pengelola zakat nasional.

Seiring dengan berkembangnya ilmu pengetahuan, pengelolaan zakat di Indonesia juga mulai diakui sebagai transaksi akuntansi oleh Ikatan Akuntan Indonesia. Hal ini ditunjukkan dengan dibuatnya PSAK 109 yang didalamnya terdapat aturan mengenai akuntansi Syariah termasuk aturan mengenai pengelolaan zakat dari segi akuntansi. PSAK 109 diresmikan oleh IAI pada akhir tahun 2011. Berlakunya PSAK 109 dapat menjadikan acuan dan pedoman oleh semua BAZ, LAZ maupun OPZ lainnya dalam pengelolaan dana zakat di Indonesia.

Dalam standarisasi PSAK 109, dapat diketahui tentang bagaimana suatu transaksi dapat dicatat, diakui/kapan diakui, bagaimana mengukurnya, hingga dalam bentuk laporan keuangan. Keuntungan bagi OPZ yang mau menerapkan PSAK 109 khususnya dalam pembuatan laporan keuangannya adalah laporan keuangan Organisasi Pengelola Zakat yang sesuai dalam PSAK 109 dapat diaudit pelaporan keuangannya oleh kantor akuntan publik maupun setingkat BPK/KPK. Pada umumnya dalam komponen laporan keuangan pada perusahaan terdiri dari Neraca, Laporan Perubahan Ekuitas, Laporan Arus Kas, Laporan Laba/Rugi, dan Catatan atas Laporan Keuangan. Namun, didalam PSAK 109 menyatakan bahwa komponen laporan keuangan yang lengkap dari Organisasi Pengelola Zakat ialah 
terdiri dari Neraca, Laporan Perubahan Dana, Laporan Arus Kas, Laporan Perubahan Aset Kelolaan, Dan Catatan atas Laporan Keuangan. Dengan pernyataan tersebut, tidak dipungkiri lagi bahwa semua komponen harus lengkap dalam pertanggung jawaban pengelolaan dana zakat oleh Organisasi Pengelola Zakat.

Saat ini masyarakat berharap bahwa mereka dapat melihat dan mengetahui dana yang mereka titipkan pada OPZ melalui laporan keuangan. Berdasarkan penelitian, 97\% masyarakat berharap OPZ bekerja secara transparan dan akuntabel oleh masyarakat, sedangkan $90 \%$ masyarakat menginginkan adanya ketidaksulitan dalam mengkases data laporan keuangan dan meminta untuk dipublikasikan di berbagai media (Rahman, 2015). Maka dari itu, tiap OPZ diharuskan untuk menerapkan transparansi dan akuntabilitas laporan keuangannya. Transparansi adalah proses fundamental dalam berdemokrasi karena seluruh warga negara dapat melihat secara lengkap aktivitas dari kegiatan kepemerintahan atau kegiatan suatu lembaga/badan usaha (Katz, 2004 dalam Ferarow \& Suprihanto, 2018). Dengan transparansi, masyarakat berhak memperoleh informasi, mengetahui, mengawasi, menilai dan menganalisa suatu kegiatan pemerintah atau lembaga/badan usaha yang mereka jalankan. Transparansi sering dikaitkan dengan sistem kelola keuangan pemerintahan, namun dalam organisasi layanan publik harus menerapkan transparansi. Oleh karena itu, setiap badan pemerintah maupun organisasi pelayanan masyarakat wajib untuk menerapkan transparansi pengelolaan keuangannya yang mana dalam penerapan tersebut merupakan prinsip dalam akuntansi sektor publik (I Made \& Rasmini, 2019).

Akuntabilitas adalah salah satu landasan umum dalam penyelenggaraan pengelolaan tata negara. Akuntabilitas adalah perbuatan pertanggungjawaban oleh seorang atau kelompok yang bertindak sebagai pihak pengelola (amil zakat) kepada pihak eksternal (muzaki) (Agustinawati \& Mawardi, 2018). Akuntabilitas finansial adalah landasan pertanggungjawaban yang dilaksanakan badan atau lembaga kepemerintahan dalam mengelola dana masyarakat secara efektif, efisien, dan ekonomis (I Made \& Rasmini, 2019). Rashid (2008) menyatakan bahwa tidak terwujudnya penerapan akuntabilitas karena adanya indikasi ketidakjujuran, korupsi dan kesalahan pengelolaan (Ihsan, Sulaiman, Alwi, \& Adnan, 2017). Beliau percaya bahwa fenomena ini disebabkan kurangnya akidah dan fiqih dalam pengelolaan dana yang mengakibatkan tiga kejadian yang telah disebutkan (Ihsan et al., 2017).

Penelitian terdahulu baru meneliti tentang praktik transparansi dan akuntabilitas di satu obyek OPZ (Indrarini \& Surya Nanda, 2017) (Ihsan et al., 2017) (Rahman, 2015) (Amelia \& Qibtiyah, 2015). Sedangkan penelitian ini berusaha mengobservasi mengenai pelaksanaan transparansi dan akuntabilitas OPZ dengan mengkomparasikan dua OPZ yang berbeda basis pengelolaan. Oleh karena itu, penelitian ini memilih BAZNAS Kota Yogyakarta dan LazizMu Kota Yogyakarta sebagai obyek penelitian. Alasan utama dipilihnya kedua obyek tersebut adalah kedua lembaga tersebut sudah termasuk OPZ yang memiliki izin resmi pemerintahan dengan pengelolaan berskala nasional. Hal ini berdasarkan asumsi bahwa OPZ yang sudah mengantongi izin dari pemerintah tentu akan melakukan pengelolaan organisasi yang sesuai standar. Sedangkan secara khusus alasan BAZNAS Kota Yogyakarta dipilih adalah karena BAZNAS Kota Yogyakarta merupakan Badan Amil Zakat yang dibentuk berdasarkan Surat Keputusan dari Kepala Daerah Tingkat II. Sumber penerimaan tetap BAZNAS Kota Yogyakarta berasal dari pengutan gaji PNS yang beragama Islam dilingkungan instansi pemerintahan Kota Yogyakarta. BAZNAS juga ditunjuk sebagai badan koordinator pengelola zakat nasional dalam UU No.23 Tahun 2011. Pemilihan LazisMu sebagai obyek penelitian juga berdasarkan alasan khusus yaitu bahwa LazisMu adalah Lembaga Amil Zakat yang dibentuk oleh Organisasi Islam yang cukup besar di Indonesia yaitu Muhammadiyah. Kota Yogyakarta adalah basis sekaligus tempat berdirinya Muhammadiyah sehingga banyak warga Muhammadiyah yang mempercayakan pembayaran zakat, infaq dan sedekahnya ke LazizMu. 
Dengan dipilihnya BAZNAS Kota Yogyakarta dan LazizMu Kota Yogyakarta diharapkan keterwakilan OPZ yang merupakan Lembaga zakat yang dibentuk pemerintah dan Lembaga zakat yang dibentuk swasta dapat diperoleh.

\section{METODE PENELITIAN}

Penulis menggunakan Metode Deskriptif Kualitatif dalam pelaksanakan penelitian. Metode Deskriptif Kualitatif adalah sebuah metode penelitian dimana penulis akan mengumpulkan bermacam data-data terlebih dahulu dari suatu obyek kemudian akan dilakukan klarifikasi, analisis, dan kemudian akan disajikan secara sistematis dan akurat sehingga akan memberikan gambaran yang jelas terhadap obyek yang diteliti (Nikmatuniayah, 2018). Penelitian ini menggunakan pendekatan multiple case study yaitu penelitian studi kasus yang menggunakan jumlah kasus yang jamak atau lebih dari satu (Nikmatuniayah, 2018). Penulis memilih studi kasus jamak karena ini dipandang bahwa dapat memahami secara menyeluruh dalam kasus yang berbeda dari BAZNAS Kota Yogyakarta dan Lazismu Yogyakarta yang akan diteliti oleh penulis.

Penelitian ini juga menggunakan pendekatan penelitian perbandingan untuk membandingkan apakah BAZNAS Kota Yogyakarta dan Lazismu Kota Yogyakarta telah akuntabel dan transparan dalam melaporkan keuangan tahunannya (Wungow et al., 2019). Analisis data pada penelitian ini menggunakan metode studi kasus dengan melihat kasus pengelolaan laporan keuangan berdasarkan PSAK Nomor 109, lalu menilai akuntabilitas dan transparansi pada BAZNAS dan Lazismu di Kota Yogyakarta dari 3 unsur pokok yaitu penyajian dan publikasi laporan keuangan sesuai dengan tenggat waktu, pertanggungjawaban penggunaan dana ZIS dan adanya audit dari lembaga eksternal, KAP, maupun dari badan atau komisi pemerintahan (Indrarini \& Surya Nanda, 2017).

Jenis data yang digunakan penulis dalam penelitian ini adalah data kuantitatif. Data kuantitatif adalah data statistik, grafik dan semacamnya yang menjelaskan laporan keuangan tahunan. Data yang digunakan dalam penelitian ini adalah data primer dan sekunder. Data primer adalah Data primer diperoleh langsung di lokasi populasi dan sampel apabila terdapat kekurangan beberapa data yang diperlukan, sedangkan data sekunder diperoleh dari website yang telah dipublikasikan di halaman website resmi sampel.

Teknik pengumpulan data yang digunakan antara lain adalah wawancara, observassi, dan dokumentasi. Penulis melakukan tanya jawab langsung kepada pimpinan atau pengelola BAZNAS dan Lazismu di Kota Yogyakarta, Daerah Istimewa Yogyakarta untuk mengklarifikasi pengakuan, pengukuran, pengungkapan, dan penyajian laporan keuangan. Penulis telah mengkonfirmasi kepada kedua narasumber yaitu: Noorlia Dharmawati, S.E. sebagai pimpinan atau pengelola BAZNAS Kota Yogyakarta yang akan disebut sebagai informan 1. H.M. Arifin, A.Md., RO. S.E. sebagai pimpinan atau pengelola Lazismu Kota Yogyakarta yang akan disebut sebagai informan 2. Setelah itu, Penulis melakukan penghimpunan data dan dokumentasi yang terdapat pada obyek penelitian yaitu BAZ dan LAZ di Kota Yogyakarta berupa arsip laporan keuangan tahunan pada tahun 2016-2018 lalu penulis melakukan pengamatan langsung ke obyek penelitian yaitu BAZ dan LAZ di Kota Yogyakarta untuk memperoleh data yang akurat dan tepat.

\section{HASIL DAN PEMBAHASAN}

Pengakuan dan pengungkapan Berdasarkan PSAK Nomor 109. Penulis telah melakukan wawancara dan observasi kepada pimpinan BAZNAS Kota Yogyakarta dan Lazismu Kota Yogyakarta bahwa hasil tersebut menunjukan penerapan dalam pengakuan dan 
pengungkapan transaksi zakat, infaq, dan sedekah pada beberapa point di PSAK Nomor 109 pada Tabel 1.

Komponen Laporan Keuangan. Komponen laporan keuangan pada PSAK Nomor 109 adalah terdiri dari:

a. Laporan Posisi Keuangan.

b. Laporan Perubahan Dana.

c. Laporan Arus Kas.

d. Laporan Aset Kelolaan.

e. Catatan atas Laporan Keuangan.

Penulis telah mendapatkan data laporan keuangan 3 tahun terakhir mealalui data primer maupun sekunder di BAZNAS Kota Yogyakarta dan Lazismu Kota Yogyakarta. Hasil dalam pengambilan data di lapangan antara lain:

a. BAZNAS Kota Yogyakarta telah melaporkan laporan keuangannya dalam 3 tahun terakhirnya sesuai dengan Pernyataan Standar Akuntansi Keuangan (PSAK) Nomor 109.

b. Lazismu Kota Yogyakarta hanya menyusun Laporan Arus Kas pada tahun 2018.

Komponen laporan keuangan yang lengkap dapat memberikan informasi yang nantinya akan menuntukan keputusan manajer atau pimpinan dalam menjalankan usaha atau kegiatannya. Berikut klasifikasi komponen pelaporan keuangan dalam Tabel 2.

Penyajian Laporan Posisi Keuangan. Penyajian laporan posisi keuangan pada Organisasi Pengelola Zakat yang diatur oleh PSAK Nomor 109 pada paragraph 34 yang berbunyi: "Amil (OPZ) dalam menyajikan laporan posisi keuangan terkait dana zakat, dana infaq/sedekah, dana operasional amil, dan dana nonhalal disusun secara terpisah dalam neraca". BAZNAS Kota Yogyakarta telah menyusun Laporan Posisi Keuangannya sesuai PSAK Nomor 109 paragraf 34. Sedangkan pada Lazismu Kota Yogyakarta belum terlihat dalam menerapkannya karena belum tersedianya laporan keuangan yang lengkap dan memadai. Hal tersebut telah terbukti pada Tabel 3.

Akuntabilitas dan Transparansi Laporan Keuangan. Harapan muzaki dalam melaporan keuangan kegiatan pengelolaan dana zakat, infaq, dan sedekah serta informasi lainnya dapat mempertanggungjawabkan yang di terbitkan ke berbagai media sebagai landasan bahwa kegiatan tersebut memang dapat dipercaya. Akuntabilitas dapat dilihat dari 3 unsur yaitu penyajian dan publikasi laporan keuangan sesuai dengan batas waktu pelaporan, pertanggungjawaban penggunaan dana ZIS dan adanya audit dari lembaga eksternal maupun dari badan pemerintahan. Dari ketiga unsur tersebut dapat diuraikan sebagai berikut:

a. Pertanggung jawaban penggunaan dana zakat, infaq, dan sedekah.

Menurut informan 1:

"Kami selalu mengupdate laporan Pertanggung jawaban ke publik yaitu membuat laporan triwulan ( 3 bulan), semester ( 6 bulan), dan tahunan. Baik laporan keuangan maupun dokumentasi laporan pentasyarufan ke mustahik yang ada di Kota Yogyakarta dan sekitarnya. Setiap kegiatannya memang atau selalu mempublikasi ke media sosial sebagai wujud akuntabilitas dan transparansi publik".

Menurut informan 2:

"Kalau bentiuk pertanggungjawaban memang kami menerima laporan berkala, ada bulanan dan tahunan dan itu hasil dari pencatatan harian untuk bulanan dan rekapitulasi bulanan untuk tahunan".

Kedua informan sama-sama melakukan pertanggung jawaban dana zakat, infak, dan sedekah hanya saja ada perbedaan jarak waktu dalam penyampaian pelaporan. Masyarakat akan menjadi percaya bahwa dana zakat, infaq, dan sedekah yang dititipkan ke BAZNAS maupun Lazismu Kota Yogyakarta telah disalurkan ke masyarakat membutuhkan. 
b. Publikasi laporan keuangan sesuai dengan batas waktu.

Organisasi Pengelola Zakat dapat mempublikasi laporan kegiatannya melalui berbagai media yang mudah diakses bagi para muzaki atau seluruh masyarakat dalam mempertanggung jawabakan pengunaan dana zakat, infaq, dan sedekah. Organisasi Pengelola Zakat akan memperoleh kepercayaan dari masyarakat untuk terus membayarkan zakat, infaq, dan sedekahnya melalui Organisasi Pengelola Zakat tersebut. BAZNAS Kota Yogyakarta telah dinilai sudah menerapkan hal tersebut. BAZNAS Kota Yogyakarta telah mempublikasi laporannya melalui media cetak maupun media digital seperti halaman website resmi BAZNAS Kota Yogyakarta. Di dalam halaman website resminya terdapat laporan-laporan dari tahun 2010 hingga 2018. Sedangkan pada Lazismu Kota Yogyakarta melaporkan laporan-laporannya melalui media digital yaitu dengan media grup WhatsApp dan halaman website resmi Pimpinan Daerah Muhammadiyah Kota Yogyakarta, akan tetapi laporan keuangan belum tersedia hingga saat ini.

c. Audit dari lembaga eksternal maupun pemerintah.

Menurut informan 1:

"BAZNAS Kota Yogyakarta tiap tahunnya di audit oleh KAP Independen dari tahun 2011 hingga tahun 2018 yang tiap tahunnya beropini Wajar Tanpa Pengecualian (KAP Inares dan Kumalahadi Kuncoro)".

Menurut informan 2:

"Pada kondisi seperti ini laporan keuangan kami masih terbilang terbaik karena telah diaudit oleh LPPK Muhammadiyah".

Kedua informan sama-sama menyatakan bahwa laporan keuangannya diaudit akan tetapi BAZNAS Kota Yogyakarta diaudit oleh Kantor Akuntan Publik. Sedangkan Lazismu Kota Yogyakarta diaudit oleh lembaga internal. Pada saat pengobservasian penulis tidak menerima bukti fisik maupun digital baik di kantor maupun halaman website resmi terkait laporan keuangan Lazismu Kota Yogyakarta. 


\begin{tabular}{|c|c|c|c|c|}
\hline No. & PSAK Nomor 109 & $\begin{array}{c}\text { BAZNAS Kota } \\
\text { Yogyakarta }\end{array}$ & $\begin{array}{c}\text { Lazismu Kota } \\
\text { Yogyakarta }\end{array}$ & Keterangan \\
\hline 1 & $\begin{array}{l}\text { Penambah dana zakat diterima dan } \\
\text { diakui dari Penerimaan zakat ketika } \\
\text { muzaki membayar melalui tunai atau } \\
\text { non-tunai. }\end{array}$ & Sesuai & Sesuai & \\
\hline 2 & $\begin{array}{l}\text { Apabila berbentuk tunai saat diterima, } \\
\text { pengakuannya sebesar jumlah yang } \\
\text { diterima namum jika berbentuk non- } \\
\text { tunai maka sesuai nilai wajar aset. }\end{array}$ & Sesuai & Sesuai & \\
\hline 3 & $\begin{array}{l}\text { Metode harga pasar digunakan dalam } \\
\text { penentuan nilai wajar aset non-tunai } \\
\text { yang diterima. Apabila metode tersebut } \\
\text { tidak tersedia, maka metode penentuan } \\
\text { nilai wajar yang lain bisa digunakan asal } \\
\text { sesuai dengan PSAK yang relevan. }\end{array}$ & Sesuai & Sesuai & \\
\hline 4 & $\begin{array}{l}\text { Jika penentuan mustahik yang } \\
\text { menerima penyaluran zakat ada di } \\
\text { tangan muzaki melalui amil, maka aset } \\
\text { zakat yang diterima semua diakui } \\
\text { sebagai dana zakat. Tidak ada bagian } \\
\text { amil atas zakat yang diterima. } \\
\text { Amil dapat menerima ujrah/fee atas } \\
\text { kegiatan penyaluran zakat laludiakui } \\
\text { sebagai penambah dana amil. }\end{array}$ & Sesuai & Sesuai & \\
\hline 5 & $\begin{array}{l}\text { Pengurang dana zakat diakui dari } \\
\text { penurunan nilai aset zakat jika bukan } \\
\text { dikarenakan oleh kesalahan amil. Jika } \\
\text { amil yang melakukan kesalahan, maka } \\
\text { kerugian ditanggung oleh amil. }\end{array}$ & Sesuai & Sesuai & \\
\hline 6 & $\begin{array}{l}\text { Pengurang dana zakat diakui dari Zakat } \\
\text { yang ditasyarufkan pada mustahik, } \\
\text { dengan keterangan sesuai dengan } \\
\text { kelompok mustahik sebesar jumlah yang } \\
\text { diserahkan dalam bentuk tunai maupun } \\
\text { non-tunai. }\end{array}$ & Sesuai & Sesuai & \\
\hline 7 & $\begin{array}{l}\text { Amil berhak mengambil bagian dari } \\
\text { zakat, infaq, dan sedekah untuk } \\
\text { membiayai kegiatan operasional sesuai } \\
\text { fungsinya. }\end{array}$ & Sesuai & Sesuai & $\begin{array}{l}\text { Hak Amil dari } \\
\text { zakat } \leq 12,5 \% \\
\text { dan } \\
\text { infaq/sedekah } \leq \\
20 \% \text {. }\end{array}$ \\
\hline 8 & $\begin{array}{l}\text { Beban penghimpunan dan } \\
\text { pentasyarufan zakat harus diambil } \\
\text { dari porsi amil }\end{array}$ & Sesuai & Sesuai & \\
\hline 9 & $\begin{array}{l}\text { Zakat dikatakan telah ditasyarufkan } \\
\text { kepada mustahik-non-amil hanya jika } \\
\text { telah diterima langsung oleh mustahik- } \\
\text { non-amil tersebut. }\end{array}$ & Sesuai & Sesuai & \\
\hline 10 & $\begin{array}{l}\text { Jika zakat disalurkan melalui amil } \\
\text { lainnya, maka zakat diakui } \\
\text { sebagai piutang penyaluran. Amil } \\
\text { penerima mengakuinya sebagai } \\
\text { utang penyaluran. Piutang dan } \\
\text { utang berkurang ketika zakat } \\
\text { disalurkan. Amil lain tidak berhak }\end{array}$ & Sesuai & Sesuai & \\
\hline
\end{tabular}


mengambil bagian dari dana zakat, tetapi bisa mendapatkan ujrah/fee dari amil sebelumnya.

Pengakuan secara bertahap diakui dari dana zakat yang disalurkan dalam bentuk perolehan aset tetap (aset kelolaan) dengan syarat aset tetap tersebut masih di dalam

11 pengendalian amil. Jika aset tetap tersebut sudah diserahkan untuk dikelola oleh pihak lain, maka diakui sebagai penyaluran zakat seluruhnya.

$\begin{array}{lr}\text { Amil diwajibkan } & \text { untuk } \\ \text { mengungkapkan hal-hal } & \text { terkai } \\ \text { dengan transaksi } & \text { zakat yaitu }\end{array}$ kebijakan penyaluran zakat untuk amil dan mustahik non-amil, metode penentuan nilai wajar yang digunakan untuk penerimaan zakat berupa aset non-tunai, rincian jumlah beban pengelolaan dan jumlah penerimaan zakat, dan hubungan istimewa antara amil dengan mustahik.

Amil harus melaporkan hal-hal-hal terkait dengan transaksi infaq/sedekah yaitu kebijakan pentasyarufan dana infaq/sedekah (skala prioritas mustahik non-amil), metode penentuan nilai wajar aset non-tunai, pembagian antara dana amil dengan non-amil, dan eksistensi dana infaq/sedekah yang tidak langsung ditasyarufkan.

Sumber data diolah, 2019
Sesuai Sesuai

Sesuai Tidak Sesuai

Sesuai Tidak Sesuai

Tabel 2. Komponen Laporan Keuangan

\begin{tabular}{llcccccc}
\hline No. & $\begin{array}{c}\text { Komponen Laporan Keuangan pada } \\
\text { PSAK No. 109 }\end{array}$ & \multicolumn{3}{c}{$\begin{array}{c}\text { BAZNAS Kota } \\
\text { Yogyakarta }\end{array}$} & \multicolumn{4}{c}{$\begin{array}{c}\text { Lazismu Kota } \\
\text { Yogyakarta }\end{array}$} \\
& 2016 & 2017 & 2018 & 2016 & 2017 & 2018 \\
\hline 1 & Laporan Posisi Keuangan & $\checkmark$ & $\checkmark$ & $\checkmark$ & $\times$ & $\times$ & $\times$ \\
2 & Laporan Arus Kas & $\checkmark$ & $\checkmark$ & $\checkmark$ & $\times$ & $\times$ & $\checkmark$ \\
3 & Laporan Perubahan Dana & $\checkmark$ & $\checkmark$ & $\checkmark$ & $\times$ & $\times$ & $\times$ \\
4 & Laporan Aset Kelolaan & $\checkmark$ & $\checkmark$ & $\checkmark$ & $\times$ & $\times$ & $\times$ \\
5 & Catatan atas Laporan Keuangan & $\checkmark$ & $\checkmark$ & $\checkmark$ & $\times$ & $\times$ & $\times$
\end{tabular}

Sumber data diolah, 2019

Keterangan:

$\boldsymbol{V}=$ data tersedia

$\mathbf{X}=$ data tidak tersedia 
Tabel 3. Penyajian Laporan Keuangan (dalan Rupiah)

Data diolah, 2019

\begin{tabular}{|c|c|c|c|}
\hline \multicolumn{4}{|l|}{ ASET } \\
\hline \multicolumn{4}{|l|}{ Aset Lancar } \\
\hline \multicolumn{4}{|l|}{ Kas dan Setara Kas } \\
\hline Kas di Tangan & 83.733 .416 & 11.529 .800 & 28.571 .448 \\
\hline Kas di Bank & - & 47.407 .640 & 31.866 .564 \\
\hline Jumlah Aset Lancar & 83.733 .416 & 58.937 .440 & 60.438 .012 \\
\hline \multicolumn{4}{|l|}{ Aset Tetap dan Aset Kelolaan } \\
\hline Aset Tetap & - & - & 57.400 .500 \\
\hline Akumulasi Penyusutan & & - & $(7.364 .458)$ \\
\hline Aset Kelolaan & - & 318.500 .000 & 312.500 .000 \\
\hline Akumulasi Penyusutan & - & 11.063 .625 & - \\
\hline Jumlah Aset Tetap dan Aset Kelolaan & - & 329.563 .625 & 362.536 .042 \\
\hline Jumlah Aset & 83.733 .416 & 388.501 .065 & 422.974 .054 \\
\hline \multicolumn{4}{|l|}{ LIABILITAS DAN SALDO DANA } \\
\hline \multicolumn{4}{|l|}{ Liabilitas Jangka Pendek } \\
\hline Utang Penyaluran & - & - & - \\
\hline Utang Dari Pihak Ketiga & - & - & - \\
\hline Jumlah Liabilitas Jangka Pendek & - & - & - \\
\hline \multicolumn{4}{|l|}{ Saldo Dana } \\
\hline Saldo Dana Zakat & 66.044 .675 & 24.543 .207 & 4.483 .505 \\
\hline Saldo Dana Infaq/Sedekah & 4.369 .876 & 342.921 .792 & 355.749 .761 \\
\hline Saldo Dana Amil & 4.373 .532 & 13.210 .892 & 51.431 .258 \\
\hline Saldo Dana Non Halal & 8.945 .342 & 7.825 .174 & 11.309 .530 \\
\hline Jumlah Saldo Dana & 83.733 .425 & 388.501 .065 & 422.974 .054 \\
\hline Jumlah Liabilitas dan Saldo Dana & 83.733 .416 & 388.501 .065 & 422.974 .054 \\
\hline
\end{tabular}

\section{KESIMPULAN}

Berdasarkan hasil analisis data maka dapat disimpulkan bahwa BAZNAS Kota Yogyakarta dinilai sudah akuntabel dalam pelaporan keuangan tahunannya, hal ini dibuktikan bahwa BAZNAS Kota Yogyakarta telah menerapkan laporan keuangan tahunan sesuai dengan PSAK Nomor 109 yang berlaku di Indonesia. Selain itu, pengakuan, pengungkapan, penyajian serta komponen laporan keuangan telah tersusun lengkap pada muatan laporan keuangan tahunan BAZNAS Kota Yogyakarta pada tahun 2016-2018. BAZNAS Kota Yogyakarta juga mempermudah masyarakat terutama para muzakinya untuk dapat mengakses dalam penyampaian laporan keuangan, lalu pelaporan keuangan sesuai tenggat waktu, serta laporan keuangannya diaudit oleh lembaga eksternal. Lazismu Kota Yogyakarta dinilai belum akuntabel dalam pelaporan keuangan tahunannya, hal ini dibuktikan bahwa Lazismu Kota Yogyakarta belum menerapkan laporan keuangan tahunan sesuai dengan PSAK Nomor 109 yang berlaku di Indonesia. Terdapat beberapa kelemahan dalam sistem pencatatan, SOP, dan juga SDM yang ahli dalam akuntansi. Selain itu, masyarakat juga belum bisa mengakses informasi laporan keuangan karena Lazismu Kota Yogyakarta belum mempublikasinya melalui berbagai media.

Penelitian ini memiliki beberapa keterbatasan diantaranya yaitu dikarenakan penelitian ini merupakan studi kasus, maka hasil penelitian tidak dapat digeneralisasikan ke semua OPZ di Indonesia meskipun penelitian ini sudah berusaha mengambil obyek penelitian yang paling mungkin mewakili kondisi OPZ. Saran bagi penelitian selanjutnya adalah pergunakan obyek penelitian yang lebih banyak agar informasi yang didapatkan dapat lebih kompleks. 


\section{DAFTAR PUSTAKA}

Agustinawati, V., \& Mawardi, R. 2018. "Memaknai Amanah Atas Praktik Akuntabilitas pada Organisasi Amil Zakat Nurul Hayat Surabaya". Jurnal Akuntansi Universitas Jember, 16 (2), 119-129.

Ferarow, N., \& Suprihanto, J. 2018. "Implementasi Pengelolaan Keuangan Desa Sumberadi dan Tlogoadi di Kabupaten Sleman: Evaluasi Praktik Transparansi dan Akuntabilitas". Jati: Jurnal Akuntansi Terapan Indonesia, 1 (2), 64-69.

Fuadi. 2016. "Model dan Peranan Lembaga Zakat". Jurnal Akad, 1 (1), 104-119.

Hastuti, Q. W. 2016. "Infaq tidak dapat dikategorikan sebagai pungutan liar". Jurnal Zakat Dan Wakaf, $3(1), 41-62$.

I Made, Y. P. D., \& Rasmini, N. K. 2019. "Pengaruh Akuntabilitas, Transparansi, dan Partisipasi Masyarakat Pada Efektivitas Pengelolaan Dana Desa". E-Jurnal Akuntansi, 28 (1), 132-158.

Ihsan, H., Sulaiman, M., Alwi, N. M., \& Adnan, M. A. 2017. A study of accountability practice in Dompet Dhuafa Waqf of Indonesia. Journal of King Abdulaziz University, Islamic Economics, 30 (2), 13 32.

Indrarini, R., \& Surya Nanda, A. 2017. "Transparansi Dan Akuntabilitas Laporan Keuangan Lembaga Amil Zakat: Perspektif Muzaki Upz Bni Syariah". AKRUAL: Jurnal Akuntansi, 8 (2), 166-178.

Nikmatuniayah, N. 2018. "Komparasi Sistem Pengendalian Internal Pengelolaan Lembaga Amil Zakat". Jurnal Akuntansi Multiparadigma, 5 (3), 498-510.

Rahman, T. 2015. "Akuntansi Zakat, Infak dan Sedekah (PSAK 109): Upaya Peningkatan Transparansi dan Akuntabilitas Organisasi Pengelola Zakat (OPZ)". Muqtasid: Jurnal Ekonomi Dan Perbankan Syariah, 6 (1), 141-164.

Wungow, A., Worang, F. G., \& Saerang, R. T. 2019. "A Comparative Analysis of Male and Female Customers Perception of Brilink Pos Terminal Performance in Manado". Jurnal EMBA, 7 (4), 4601-4609.

Amelia, E., \& Qibtiyah, M. 2015. "Perlakuan Akuntamsi Zakat Berdasarkan PSAK 45 dan PSAK 109 Pada BAMUIS BNI". The Journal of Tauhidinomics, 1 (2), 183-198. 